\title{
Ensayos de metafísica y epistemología
}

\section{Gustavo Ortiz Millán}

\author{
Guillermo Hurtado, Por qué no soy falibilista \\ $y$ otros ensayos filosóficos. \\ México, Los Libros de Homero, 2009, 87 pp.
}

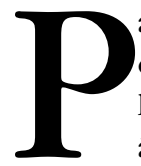

ara quienes, de una u otra manera, nos hemos formado en la tradición analítica y estamos más o menos al tanto de lo que ocurre en la filosofía contemporánea, nos resulta muy extraño que en algunos ámbitos filosóficos se afirme que la filosofía analítica es antimetafísica. Se suele pensar que la analítica, siendo la heredera del positivismo lógico, debe ser igualmente hostil a la metafísica; pero es erróneo pensar que la analítica contemporánea es positivista -o que lo es mayormente- y también lo es pensar que es antimetafísica. Hay mucha metafísica en la filosofía analítica contemporánea.

El positivismo lógico, según el título del famoso artículo de Rudolf Carnap, proponía la superación de la metafísica por medio del análisis lógico del lenguaje. Carnap sostenía que las proposiciones de la metafísica carecían de sentido, ya que no eran verificables empíricamente. Lo que había que hacer era abandonar la metafísica como parte del quehacer filosófico serio y riguroso. Sin embargo, para mediados del siglo $\mathrm{xx}$, el proyecto positivista había mostrado ya sus limitaciones y muchos lo consideraban un proyecto fracasado. Las críticas del segundo Wittgenstein, Quine, Popper y la escuela del lenguaje común hicieron que muchos vieran ese proyecto como inviable. Y aunque el positivismo fue, en cierto sentido, un proyecto muy fructífero (sobre todo porque de él surgió la filosofía analítica contemporánea), también fue una manera muy estrecha de hacer filosofía. No sólo condenaba a la filosofía a ser la guardiana de la significatividad del lenguaje científico, sino que tiraba por la borda a la metafísica, a la ética, la estética y la filosofía política. Pasarían muchos años antes de que estas áreas empezaran a desarrollarse dentro de esta tradición. La ética, la estética, la filosofía política y social e incluso la filosofía de la religión son áreas ahora muy desarrolladas dentro del quehacer analítico. La metafísica tardó en desarrollarse, pero poco a poco se ha convertido en una de las áreas centrales del quehacer de los filósofos analíticos contemporáneos. Desde los 
años sesentas, diversos filósofos analíticos se han abocado al problema de la identidad personal, al problema mente-cuerpo, al tema de los sucesos o al de la libertad de la voluntad, que son temas netamente metafísicos. Sin embargo, supongo que no fue sino con filósofos como Chisholm, Davidson, Armstrong, Wiggins, Kripke y, sobre todo, David Lewis, que la metafísica como tal cobró relevancia dentro de la tradición analítica. Hoy en día no hay congreso de filosofía analítica que no incluya temas de mereología, objetos, partes, propiedades, sucesos, disposiciones, causalidad o la naturaleza del tiempo, entre otros muchos. Ahora, yo no estoy seguro de que la filosofía analítica, incluso en sus momentos más antimetafísicos como con el positivismo lógico, haya sido efectivamente antimetafísica: sus tesis centrales ya conllevaban posiciones metafísicas y distintos compromisos ontológicos. Tal vez filósofos como Nietzsche, Derrida o muchos posmodernos, que son enemigos explícitos de la metafísica, sean más antimetafísicos incluso que los positivistas.

Ahora bien, es curioso que dentro del contexto de la filosofía analítica latinoamericana la metafísica se haya desarrollado muy poco -y sería interesante preguntarse por qué. Aunque de algún modo todos tomamos, a veces consciente, a veces inconscientemente, posiciones metafísicas al hacer filosofía (por ejemplo, al hacer filosofía de la mente, del lenguaje, de la ciencia, ética o estética), son muy pocos quienes dedican sus esfuerzos centrales a la metafísica propiamente dicha. Por lo menos en el contexto mexicano, Guillermo Hurtado ha sido uno de los pocos filósofos analíticos abocados directamente a cuestiones metafísicas.

Ya en su libro Proposiciones russellianas, de 1998, Hurtado abordaba diversos problemas metafísicos y ontológicos. En aquel libro ofrecía una teoría ontológica de la lógica cuantificacional de primer orden. Proponía una teoría ontológica de la naturaleza de proposiciones, formas lógicas y de la cuantificación, distinta de las de Frege, Russell y Wittgenstein. Su nuevo libro, Por qué no soy falibilista y otros ensayos filosóficos, continúa, en buena medida, su preocupación por la metafísica y la ontología. Este libro recoge seis ensayos que publicó antes como artículos en revistas especializadas o como capítulos de libros. Los tres primeros abordan temas de metafísica, los otros tratan temas de epistemología, un área mucho más cultivada en nuestro medio, pero sobre la que el autor tiene cosas muy interesantes que decir. Los ensayos son de temas muy diferentes entre sí; aunque aquí quiero dar cuenta de los distintos temas, no comentaré todos, sino que sólo me centraré en un par de ellos.

El ensayo "Cómo convertirse en otra persona sin dejar de ser uno mismo" aborda un viejo problema de la metafísica: la identidad personal a través del tiempo. Como dice Hurtado, es un tema que ocupó las mentes de muchos metafísicos analíticos en la segunda mitad del siglo pasado, pero que ha caído un poco en el olvido. Difiero de él en que son pocos los que siguen interesados 
en este tema; se sigue escribiendo sobre él y sospecho que veremos un incremento en la literatura al respecto. Entre otras cosas porque no se trata de un solo problema, sino de un conjunto de preguntas centrales para la filosofía: ¿quién soy yo?, ¿qué es una persona?, ¿cómo es que una persona puede seguir siendo la misma a través del tiempo?, ¿cómo puedo averiguar quién es quién?, ¿qué es lo que importa en la identidad?, además de otros problemas relacionados.

Hurtado sostiene que la metafísica analítica cometió dos errores al tratar el problema de la identidad personal: el de no abordar directamente el problema de qué es una persona, sino de tratar de responderlo a través de la pregunta por la identidad personal; y el de afirmar, nos dice, "con una insistencia casi parmenídea" qué es lo que hace que una persona siga siendo la misma, mientras que para Hurtado lo más evidente, nos dice de modo heraclíteo, es que la gente cambia, por eso él se pregunta "¿qué es lo que hace que alguien pueda convertirse en otra persona?” El énfasis está puesto en el cambio de una persona, no en lo que persiste -aquí Hurtado retoma un tema que aborda en el primer capítulo del libro, el de la naturaleza del cambio. Su propósito, nos dice, "[...] es presentar el esquema de una teoría metafísica sobre la persona que supere [estos] dos errores [...], es decir, la teoría que propondré parte del dato de que las personas somos seres en constante cambio, y además asume el supuesto teórico de que para decir algo sobre la identidad personal hemos de tener antes una respuesta sustantiva a la pregunta de qué es una persona" (p. 37).

Claro que uno puede preguntarse qué tan cierto es el diagnóstico de Hurtado con respecto a la metafísica analítica. A fin de cuentas, al hablar de qué es lo que hace que una persona siga siendo ella misma a través del tiempo, se está partiendo ya de una cierta concepción acerca de lo que es una persona. Al mismo tiempo, identidad y cambio son conceptos con una relación dialéctica: al hacer la pregunta por la identidad también nos estamos preguntando por el cambio. Por eso no estoy seguro de que el enfoque de Hurtado sea tan radical.

Para responder la pregunta sobre qué es una persona, Hurtado sostiene que la diferencia entre el concepto de ser humano y el de persona no es nominal ni real, sino que es modal (aquí recoge un concepto abordado en el segundo capítulo del libro, el de los modos, que discute en el contexto de la filosofía del escolástico Francisco Suárez). Persona y ser humano son dos modos (¿dos aspectos?) de un mismo ente. Así, Hurtado define a la persona como "un modo contingente de la existencia de un ser humano [...] ser una persona es algo muy poco sustancial, es apenas un modo en el que los humanos actuamos para tener un poco más de probabilidades de sobrevivir en grupo. No obstante, ser una persona es algo extraordinario en la oscura vastedad del universo. Es porque podemos ser personas que los seres humanos nos distinguimos del 
resto de las cosas. En eso y nada más consiste, a fin de cuentas, la tan mentada dignidad humana" (pp. 40-41). Así, ser humano y persona son dos modalidades de una misma entidad -dejemos por ahora el tema de la dignidad humana para más adelante. El modo "ser humano" tal vez podría definirse en términos biológicos, como aquellos seres que pertenecen a la especie Homo sapiens o que tienen el código genético propio de esa especie; eso es lo que yo infiero, no lo que Hurtado dice, porque en realidad no nos dice en qué consiste ser un ser humano. Sin embargo, lo que no termino de encontrar en su texto es qué es lo que distingue a las personas: está bien, concedamos que ser persona es un modo, pero ¿qué distingue ese modo? ¿O es acaso que todos los seres humanos son personas? ¿Entonces para qué necesitamos la distinción? Y si no todos los seres humanos son personas, ¿qué es lo que hace que lo sean o dejen de serlo? No basta con afirmar que ser persona es un modo de existir de un individuo, habría que darle sustancia y decir de manera precisa qué es lo que lo caracteriza.

Un poco antes de esta caracterización, Hurtado nos da lo que él llama "indicadores", que no condiciones necesarias, de la condición de persona. "Para que alguien sea considerado como una persona hecha y derecha debe poseer un conjunto extenso y complejo de características y habilidades. Una persona es, normalmente, alguien que piensa, razona, habla, toma decisiones, realiza tareas, tiene sentimientos y deseos, imagina, sueña, que se comunica con otras personas, que puede interpretarlas, vivir con ellas, colaborar con ellas, etc." (p. 38). Creo que hay problemas con el modo en que Hurtado caracteriza a una persona: por un lado, su lista es demasiado amplia y no nos sirve para debates en los que el concepto de persona es crucial, por ejemplo, en el debate acerca del aborto; por otro lado, alguien podría pensar que sus indicadores establecen criterios muy altos de personalidad: un individuo con discapacidades cognitivas difícilmente contaría como una persona. Eso es lo que hace complicado el asunto de qué es una persona.

Daniel Dennett -alguien que por cierto contradice la idea de Hurtado de que la metafísica analítica no se preocupó por responder la pregunta por la condición de persona directamente, sino a través de la cuestión de la identidad a través del tiempo-, en un artículo clásico sobre las condiciones de la calidad de persona, habla de ciertas condiciones - no todas necesarias y mucho menos suficientes- para decir de alguien que es una persona. ${ }^{1}$ Creo que Hurtado debería proceder de un modo similar y decirnos un poco más sobre qué es lo que hace que ese modo de ser sea una persona. Sin duda, muchas de las características que menciona deberían estar en esa caracterización, como el

${ }^{1}$ Daniel Dennett, Condiciones de la cualidad de persona. México, UNAM, Instituto de Investigaciones Filosóficas, 1989. 
modo en que nos presentamos a los otros, las circunstancias en las que nos desenvolvemos, etcétera. Si Hurtado desarrolla un poco más esta teoría de la persona nos hará un gran favor a muchos que estamos interesados en este concepto tan central para la filosofía, pero también para la vida cotidiana.

Por cierto, creo que Hurtado se equivoca al pensar que la dignidad humana consiste, a fin de cuentas, en que las personas somos algo distinto del resto de las cosas en el universo. Si la dignidad humana se reduce al concepto de persona, entonces probablemente no sería necesario hacer la diferenciación. Pero la dignidad humana no consiste simplemente en ser diferentes; tal vez sea sólo una cuestión de énfasis, pero el concepto de dignidad humana, por lo menos en su versión kantiana, está basado en la capacidad para la racionalidad práctica, particularmente en la capacidad que tenemos las personas de ser agentes autónomos que rigen sus vidas por los principios que se dan a sí mismos. Kant pensaba que esta capacidad era la fuente del valor y de la normatividad que rige nuestras vidas; dado que los seres humanos somos creadores de valor, eso nos da un valor intrínseco, diferente al valor que le asignamos a otras cosas en el mundo. Ésa es una posible respuesta al asunto de la dignidad; pero si ésta se redujera simplemente a que somos distintos de las otras cosas en el universo, eso no explicaría todavía el valor especial que tenemos las personas y que nos sirve para fundar en él, por ejemplo, nuestras teorías de derechos humanos.

Sobre la cuestión de enfocarse en el cambio o en la conversión de una persona en otra, y no en lo que permanece, Hurtado afirma: "Voy a sostener que cuando decimos de alguien que ha dejado de ser la persona que era para convertirse en otra distinta, esta afirmación puede ser verdadera en sentido literal" (p. 39). Esto suena muy radical, sin embargo, más adelante matiza: "hago la aclaración de que no sostengo que pueda convertirme en cualquier otra persona o que pudiera haber sido cualquier otra persona" (p. 41). Esto es así porque un ser humano puede actualizarse de, literalmente, distintos modos, es decir, en distintas personas a lo largo del tiempo. Recordemos que ser persona es sólo un modo en que existe y se presenta un individuo. Hurtado acepta que tanto la continuidad corporal como la psicológica son condiciones necesarias para la identidad a través del tiempo, pero no suficientes, así, a pesar de que haya esa continuidad, un individuo puede no ser la misma persona a lo largo del tiempo. Aquí es donde Hurtado enfatiza el cambio, más que la permanencia. Si ser una persona es un modo de existir de un ser humano, este modo puede instanciarse de diferentes formas dentro de un mismo ser humano en distintos tiempos. Somos distintas personas a través del tiempo. Pero tomarnos muy en serio la propuesta de Hurtado y acentuar mucho el cambio puede ser riesgoso, porque si efectivamente somos distintas personas a través del tiempo, entonces esto puede tener consecuencias prácticas serias, 
como en adscripciones de responsabilidad. Por ejemplo, no podría adscribirle responsabilidad a la persona pasada que un ser humano fue.

En contra de lo que afirma Hurtado, creo que no hay que tomar "literalmente" la idea de que uno puede convertirse en otra persona; no si el precio de aceptar el cambio implica olvidarnos de la permanencia. Aunque nos convertimos en otras personas, seguimos siendo la misma persona a través del tiempo. Cuando decimos que alguien se ha convertido en otra persona, no lo decimos literalmente: lo que queremos decir es que muchos de los rasgos característicos de un individuo han cambiado, pero también aceptamos que muchos otros permanecen y eso es lo que hace posible que nos sigamos refiriendo a esa persona como la misma persona. En el problema de la identidad personal resulta tan interesante el cambio como la permanencia. De algún modo al dar cuenta de uno damos cuenta del otro. Creo que los dos son igualmente necesarios y que hay, por así decirlo, una relación dialéctica entre ambos conceptos.

Coincido con Hurtado en que es difícil, si no es que imposible, especificar las condiciones necesarias y suficientes de la condición de persona; pero algunas condiciones (aun si son mínimas) se tienen que dar para saber cuándo es que una persona efectivamente lo es. Es importante en contextos jurídicos y morales, entre otros, y aquí creo que haría falta que Hurtado nos diera una concepción más robusta de lo que es una persona, para saber cuándo los cambios hacen que seamos otra persona o seguimos siendo la misma.

Quiero analizar ahora el ensayo que le da título al libro, "Por qué no soy falibilista". Es un artículo que nos hace detenernos a cuestionar una de esas posiciones filosóficas que muchos aceptamos tácitamente sin realmente cuestionarnos qué significa y cuáles son sus implicaciones. Muchos que probablemente piensen que el falibilismo es una teoría tan obvia y sensata que todos deberíamos adoptarla, tal vez cambien de parecer al terminar de leer este ensayo. Como afirma Hurtado, el falibilismo ha sido descrito como el término medio virtuoso entre los extremos del dogmatismo y el escepticismo -extremos que la mayoría pensamos que se deben evitar-y por ello lo hemos adoptado.

Charles Sanders Peirce, que fue quien primero acuñó el término "falibilismo", sostenía que "nunca podemos estar seguros de nada" y que "no podemos alcanzar certeza absoluta en lo que concierne a cuestiones de hecho". ${ }^{2}$ En sus versiones contemporáneas, el falibilismo sostiene que cualquiera de nuestras creencias puede resultar ser falsa. En su versión más extrema, formulada por Quine, todas nuestras creencias son contingentes, todas revisables, todas corregibles, incluso nuestras creencias matemáticas y lógicas. Aunque hay versiones

${ }^{2}$ C. S. Peirce, Collected Papers. Cambridge, Mass., Universidad de Harvard, 1931, vol. 1, p. 347. 
más débiles de falibilismo, como la que sostiene que de hecho muchas de nuestras creencias, quizá la mayoría, son falsas, Hurtado toma la versión más radical como el blanco de su crítica, la de que todas nuestras creencias pueden resultar ser falsas. También distingue ese falibilismo radical de uno más moderado que sostendría que algunas de nuestras creencias pueden resultar ser falsas; creo que pocos tendríamos objeciones para sostener una tesis como ésta, pero en realidad esto no es lo que dice el falibilista. Eso es lo que sostendría un creyente ordinario sensato que no fuera falibilista.

Hurtado sostiene que la tesis falibilista fuerte es falsa, es decir, que no todas nuestras creencias pueden resultar ser falsas. Hay algunas creencias que no admiten la posibilidad de seriamente ser puestas en duda o resultar falsas. Él menciona algunos ejemplos: la creencia de que yo pienso (que es obviamente la piedra fundacional a la que llegó Descartes después de dudar de todas sus otras creencias); la creencia de que no se cumplen todos mis deseos; de que algunas cosas suceden antes que otras, y la de que el triángulo tiene tres lados (que es analítica, verdadera por definición). La lista se puede multiplicar para abarcar creencias sobre verdades lógicas, matemáticas, analíticas, pero también otras. En todo caso, basta con que haya alguna creencia que no pueda resultar ser falsa para que la tesis falibilista fuerte sea falsa. Habría que señalar que, aunque Hurtado no lo dice, la tesis que él abraza es conocida en la literatura como "infalibilismo", que bien puede sonar como un término un poco pomposo; el infalibilismo es la tesis de que ser epistémicamente infalible acerca de una creencia es "adscribirle el mayor grado de certeza, en el sentido de que cualquier otra creencia que sea inconsistente con ella no será tomada como una posibilidad seria". ${ }^{3}$

Aquí hago un paréntesis. Mientras leía este ensayo pensaba que, aunque el falibilista tuviera razón y todas nuestras creencias, en teoría, fueran revisables y pudieran resultar ser falsas, en la práctica no todas lo son. Pensaba en un caso interesante que el politólogo estadounidense Gerry Mackie ha llamado "trampas de creencias" (belief traps), y que ilustra con el siguiente ejemplo:

Las mujeres que practican la infibulación están atrapadas en una trampa de creencias. Los bambara de Mali creen que el clítoris matará a un hombre si llega a tener contacto con el pene durante el coito. En Nigeria, algunos grupos creen que un bebé morirá si su cabeza toca el clítoris durante el parto. A éstas las llamo creencias que se imponen por

${ }^{3}$ Bengt Hansson, "Infallibility and incorrigibility", en Erick Olsson, comp., Knowledge and Inquiry: Essays on the Pragmatism of Isaac Levi. Nueva York, Universidad de Cambridge, 2006. 
sí mismas (self-enforcing-beliefs): una creencia que no puede revisarse porque los costos creídos para probar la creencia son demasiado altos. ${ }^{4}$

Aunque la creencia sería revisable en teoría, en la práctica los costos de revisarla serían tan altos que es mejor no hacerlo. Sostener estas creencias es como estar atrapado en ellas: no se pueden revisar porque hacerlo tendría costos altísimos. Aunque puede ser que éste sea un caso extremo, hay muchos otros casos más comunes de creencias cuya revisión tiene costos muy altos: revisar mis creencias de que, por ejemplo, no debo usar la rasuradora eléctrica mientras me ducho o de que no debo cruzar una autopista donde corren automóviles a toda velocidad tendría costos tan altos que es mejor no revisarlas. Estos casos no tendrían en principio por qué incomodar al falibilista, pero son interesantes porque en ellos revisión de creencias y racionalidad práctica entrarían en conflicto.

Vuelvo al texto de Hurtado. Él no se conforma con darnos contraejemplos que falseen la tesis falibilista y que nos devolverían a la versión moderada que en la vida diaria todos sostenemos; Hurtado examina los argumentos que se han dado a favor del falibilismo y nos muestra sus debilidades. Examina cuatro tipos de argumentos: (1) el argumento histórico-pragmático, que sostiene que el falibilismo se sigue de examinar la historia y la práctica científica. Muchas teorías que en algún momento se consideraron verdaderas, con el paso del tiempo se mostró que eran falsas; las creencias que sostenemos hoy, mañana podrían ser falsas. Hurtado argumenta que de esta idea no se sigue el falibilismo: "sino la tesis del sentido común de que no siempre sabemos cuándo una creencia es verdadera, ni siquiera cuándo está bien apoyada en datos y razones” (p. 51). (2) Hurtado analiza los argumentos epistemológicos que se han formulado a favor del falibilismo: el de la inducción, el de que no hay observaciones neutrales y la tesis de la subdeterminación de las teorías empíricas. No reproduciré aquí todos estos argumentos, pero de la lectura del texto no sólo se desprende que ninguno apoya la posición falibilista, sino también que Hurtado tiene una gran capacidad para resumir argumentos complejos de una manera clara y concisa. (3) Tampoco los argumentos que Hurtado llama éticos apoyan al falibilismo: éstos son los que afirman que del falibilismo se sigue la tolerancia. El falibilismo es una teoría que se ha presentado como fundamento de la tolerancia; pero detrás de una apariencia de humildad intelectual y de reconocimiento de la falibilidad y la imperfección humana hay ideas que deberíamos revisar y corregir. Hurtado argumenta que el antifalibilismo es tan buen fundamento de la tolerancia como el falibilismo, dado que la tolerancia se puede

${ }^{4}$ Gerry Mackie, "Ending Footbinding and Infibulation: A Convention Account", en American Sociological Review, vol. 61, núm. 6, diciembre, 1996, p. 1009. 
defender no por razones epistémicas, sino morales, políticas o prudenciales. Además, la tolerancia a la que se llega por el falibilismo es demasiado amplia y, nos dice Hurtado, no se puede tolerar cualquier cosa. Curiosamente, Popper -uno de los mayores defensores del falibilismo- proponía la intolerancia hacia la intolerancia. Esto muestra una tensión al interior de la teoría, no sólo en lo que se refiere a la tolerancia, sino también en lo que toca al falibilismo: así como se marca un límite a la tolerancia en lo que se refiere a la intolerancia, asimismo afirmar la verdad del falibilismo parecería marcar un límite a aquello que puede resultar ser falso. Pero mientras que para el caso de la tolerancia hay razones prácticas para marcar ese límite, no parece haber ninguna razón dentro del falibilismo para ello. En otras palabras: el falibilismo mismo puede resultar ser falso, lo que nos lleva a la paradoja de que si el falibilismo es verdadero, entonces es autorrefutable, es decir, si nuestra creencia en el falibilismo puede resultar ser falsa, entonces no sería cierto que el falibilismo es verdadero. Nos dice Hurtado: si "afirmamos que el falibilismo es una verdad indiscutible y que por ello es ilegítimo combatirlo o desobedecerlo [...], entonces está claro que el falibilismo es falso, ya que al menos una de nuestras creencias, la creencia en el falibilismo, no puede resultar ser falsa" (p. 57).

Por cierto, me llama la atención que Hurtado cite a Voltaire al hablar de la conexión entre tolerancia y falibilismo, pero no a Locke. Me parece que esta relación es mucho más clara en el filósofo inglés. Simplificando mucho, para Locke, puesto que todo conocimiento proviene de los sentidos, y éste no nos da certeza, sino diversos grados de probabilidad y dado que hay un grado en el que podemos estar equivocados, tendríamos que ser tolerantes unos con otros. Luego, Locke generalizará este argumento para creencias religiosas y políticas.

Hay toda una batería de argumentos en contra del falibilismo en el texto de Hurtado, de modo que si uno de ellos no nos convence, hay muchos más que seguramente convencerán al más escéptico... o al más falibilista.

El libro de Hurtado, aunque es pequeño, es rico en temas y en ideas. Además de los ensayos en los que me he centrado, otros ensayos abordan la cuestión de qué es un cambio, para la que nuestro autor ofrece un modelo ontológico-formal del cambio "según el cual un cambio básico es un tipo de conjunción de estados temporalmente ordenados" (p. 13), es decir, un cambio es un tipo de conjunción de estados de cosas y tiempos. También aborda un tema de Suárez, el filósofo español del siglo XVI: el tema de los entes y los modos en las Disputationes metaphisicae. Ya hemos visto que Hurtado utiliza la noción de modo para desarrollar su teoría sobre las personas. Tal vez Hurtado sea uno de los poquísimos filósofos contemporáneos que han estudiado la obra de Suárez, particularmente desde una perspectiva analítica. En los dos últimos ensayos del libro, Hurtado nos ofrece dos temas de epistemo- 
logía, un magnífico texto sobre la duda y la sospecha, y un comentario al texto de san Agustín, De utilitate credendi, en que Agustín se pregunta si debemos creer lo que no sabemos. Se trata (para usar el lugar común en las reseñas, pero que es muy cierto aquí) de un conjunto de ensayos de metafísica y epistemología que no sólo interesarán al especialista en estos temas, sino a cualquier persona interesada en temas filosóficos en general. Conozco otros escritos de Guillermo Hurtado y sé que bien podría haber incluido otros ensayos de gran calidad que ha publicado en revistas y en libros; sin embargo, en esta ocasión nos ha ofrecido un pequeño volumen en donde aborda temas complejos, pero siempre de una manera clara y concisa. Es un volumen que nos obliga a revisar nuestras creencias y a pensar con el autor los temas que va analizando. Es un libro que provoca y que incita a pensar, lo cual es en sí mismo una virtud. Pero también es el libro de alguien que va construyendo sus argumentos con mucho cuidado y sensibilidad, que gusta del lenguaje, que lo maneja con destreza y con precisión, y por eso es un deleite leer este libro. Ojalá que la filosofía -analítica o no- siempre se escribiera así, porque creo que así tiene que ser la buena filosofía. 